\title{
Cancer and the global South
}

\author{
Carlo Caduff ${ }^{1}$ - Cecilia C. Van Hollen ${ }^{1}$
}

Published online: 18 November 2019

(C) Springer Nature Limited 2019

Today, global health experts are increasingly concerned with the surge of non-communicable diseases in the global South. A key research aim over the past two decades has been to confirm that conditions such as cancer are now a major cause of death and disability in many countries of the South. Experts suggest that there has been a lack of attention to non-communicable diseases outside Europe and North America and that more needs to be done to prevent and control these conditions. A 1992 World Bank report argued that non-communicable diseases such as cancer are "major causes" of adult morbidity and mortality "throughout the developing world." However, as the report underscored, these diseases are "seriously neglected in research and policy" (Feachem et al. 1992, p. 1). A 2005 World Health Organization publication on the prevention of chronic diseases suggested that "the poorest countries are the worst affected." According to the report, "only $20 \%$ of chronic disease deaths occur in high-income countries while $80 \%$ occur in low- and middle-income countries." (WHO 2005, p. 8).

As global health experts have increasingly turned their attention to cancer in the global South through epidemiological research and the implementation of biomedical programs for the prevention and treatment of cancer, we are also witnessing the burgeoning of social science and humanities research on cancer in the South, in part as a response to the global health agenda. Anthropologists have produced several new ethnographies of cancer (Gregg 2003; Livingston 2012; Lora-Wainwright 2013; Martínez 2018) as well as two recent edited volumes that include some studies of the global South (Armin et al. 2019; Mathews et al. 2017). Historians too have published accounts of the history of cancer and cancer care globally and in specific regions of the global South during this decade (Brandt 2007; Mukherjee 2010).

Carlo Caduff

carlo.caduff@kcl.ac.uk

1 King's College London, London, UK 
In May 2017, we convened a workshop on "Cancer in the Global South: Thinking with Precarity" at King's College London. The workshop brought anthropologists and historians together in conversation to explore inter-disciplinary connections across our shared research on cancer in South Asia and sub-Saharan Africa, to consider how the idea of the "global South" itself was being framed within global and public health cancer projects and how cancer precarity is produced. In our coauthored article in the Journal of Global Oncology that followed the workshop, we argued that bringing inter-disciplinary social science and humanities approaches to bear on oncology can help to extend "the range of relevant policy agendas beyond a focus on behaviour and compliance to the more nuanced, context-specific policy challenges only discernible through long-term empirical research" (Caduff et al. 2018 , p. 2). This special issue extends this call and presents the research of several of the workshop participants.

\section{The politics of non-communicable diseases}

Drawing on Michel Foucault's work, sociologists David Reubi, Clare Herrick, and Tim Brown have examined the politics of non-communicable diseases in the global South highlighting the discursive framing of the problem (Reubi et al. 2015). Reubi, Herrick, and Brown draw attention to the material conditions, medical practices, and political rationalities "that make it possible to think about chronic diseases as a problem for developing countries today" (p. 2). In their work, they show how, why and for whom these diseases have become a problem that needs to be addressed.

The articles and photo essay in this special issue extend this work and further probe the question. The special issue pairs articles by two historians with articles by two anthropologists with one from each of these disciplines writing on India and one from each of the other disciplines writing on sub-Saharan Africa (Kenya and Rwanda). The concluding photo essay presents the work of a scholar trained at the intersection of history and anthropology, also working in sub-Saharan Africa (Uganda). The juxtaposition of these articles and the photo essay helps to appreciate differences and convergences across disciplines, across two continents, and across colonial and postcolonial timeframes. Each piece raises the fundamental question about whose interests are being served by various engagements with cancer care and cancer research in the global South. Each piece examines the political economy of knowledge and the visibilities and invisibilities that ensue. They do so from different scales, ranging from colonial empires and postcolonial configurations of international development, to contestations between governments and philanthropic organizations, to internal struggles within families.

The four articles and the photo essay take the growing concern with non-communicable diseases as a starting point to examine the stakes of locating cancer in the global South. They argue that today's framing of cancer as a crisis of noncommunicable diseases tends to erase long national and transnational histories of medical research and public health advocacy. Refusing the rhetoric of crisis that experts deploy to create attention and motivate action, the contributors examine what is accomplished through erasure. This allows us first, to address the politics 
of biomedical knowledge; second, consider how and why the idea of cancer in the global South matters to experts in the global North; and third, to situate the recent concern within longer national and transnational histories of cancer care and cancer research.

To figure out how cancer matters to the global South, we need to refuse the false clarity of crisis and question attempts to claim cancer as that which is new to the South. Jean and John Comaroff's 2012 collection of essays, entitled Theory from the South, helps us to reject false dichotomies about the relationship between the North and the South and about theories that emerge from these relationships in order to challenge assumptions about development and modernization (Comaroff and Comaroff 2012). Through their work, we can appreciate that the precarities of capital and labor, and of health and medicine in much of the global South may point to future conditions of the global North, thus debunking deeply entrenched social evolutionary views of the South as the North's past and the North as the South's future. Disparities of health, wealth, and care are not necessarily geographic-neither the South nor the North are homogeneous regions (Adams et al. 2019). All essays in this volume examine the global South while, at the same time, upsetting simplistic divisions between North and South.

Kavita Sivaramakrishnan's historical essay "An irritable state: the contingent politics of science and suffering in anti-cancer campaigns in South India" shows how physicians and women activists established a cancer relief fund, mobilized philanthropic resources, and built the first cancer hospital in South India in the 1950s. Struggling against the assumption that the disease was a malady of prosperity virtually absent in poor countries, these physicians and activists emphasized that Indians suffered from cancer as well and that the condition merited care and commitment by the state and its citizens. In fact, cancer affected "the same deprived populations that were also vulnerable to infectious diseases." As Sivaramakrishnan notes, anti-cancer campaigns in South India "invoked a Gandhian idiom of welfare, uplift and compassion" and "appealed to developmentalist paradigms and the usefulness of saving, curing and optimizing young lives stricken by cancers." They relied on a language of biomedical certainty to challenge the idea of cancer as a fatal disease. However, despite all this effort, cancer treatment and prevention remained in the private realm of philanthropy.

At the time, Nehru did not consider cancer care to rise to the level of a public health priority for the postcolonial state. He viewed it as something that would inevitably become a problem in the future as he was leading India on a path of technological development that would lead to a more prosperous society. For Nehru, cancer was a negative side effect of the success that he would usher in, but not an urgent matter of his time. The activists engaged in the anti-cancer campaigns in South India were enraged by the state's denial of the immediate suffering of cancer patients from all walks of life, rural and urban and rich and poor alike. Yet they too practiced their own forms of erasure as they campaigned ardently for the uplift of poor rural women through educational programs to prevent cancer by encouraging these women to have fewer children and to refrain from using chewing tobacco rather than addressing the social and economic conditions responsible for poor health outcomes among the rural poor at the time. 
Lucas Mueller's essay "Cancer in the tropics: geographical pathology and the formation of cancer epidemiology" traces the history of medical research on potential causes of cancer in the global South. He demonstrates how an international group of geographical pathologists primarily from Europe and North America focused intensively on cancer in the tropics from the 1920s to the 1960s. In this transnational history of medical research, liver cancer played a key role for geographical pathological research, allowing scientists to probe the role of the environment as a potential carcinogenic factor. Cancer was not considered to be a problem that was unique to the North. Yet the knowledge gained from conducting research on cancer within discreet Kenyan environments was intended to benefit European and North American scientists at a time of growing alarm over increasing rates of cancer in the post-World War II era. There was an added urgency to the work of these geographical pathologists because the Kenyan environmental laboratories were rapidly changing as a result of colonial economies. In his article, Mueller describes the scientific research as a form of "salvage epidemiology," implicitly linking this to similar projects of "salvage ethnography."

Mueller's and Sivaramakrishnan's essays both show that while knowledge about cancer in the global South existed, political action to implement cancer treatment and prevention programs did not necessarily follow. The two pieces not only reject a simplistic dichotomy between North and South but also question the processes by which these regions were made and remade through disease classifications.

\section{Experiments in meaning, morality, and social relations}

The essays by the two anthropologists draw from their ethnographic insights to demonstrate diverse ways that patients suffering from cancer and their caretakers cope with a disease that is often stigmatizing, acutely painful, and extremely expensive to treat. These challenges are exacerbated by the ever-looming shadow of uncertainty of treatment outcomes due in part to the limits of medical science and knowledge but also to the lack of resources for advanced medical treatment that disproportionally jeopardize the health of many in the global South in societies that have experienced genocide as well as colonial and postcolonial forms of global capitalist extraction.

Darja Djordjevic's article, "Pluripotent trajectories: public oncology in Rwanda" sheds light on the triumphalist nationalist narratives of Rwanda rising from the ashes first of colonialism but more recently from a brutal genocide to become a model for one of the initiatives of the Boston-based NGO, Partners in Health, to provide "first world medicine" in "third world" countries. The provision of top of the line oncology care has become a potent symbol in Rwanda's new nation-building project. Citizens are expected to renounce "superstitious" and outdated beliefs and practices associated with witchcraft and sorcery and to give their allegiance to the nationally sanctioned biomedical project of oncology. The fact that they do not is cause for much concern among members of the state and the medical establishment, who cannot appreciate how rituals of sorcery can help patients cope with the profound uncertainty of cancer treatment outcomes, particularly under conditions of scarce resources. Similar to Sivaramakrishnan's piece, here too we see how the 
emphasis on "culture" as an obstacle to health can preclude the articulation of a broader framing of medicine that "acknowledges both the limits of treatment and the diverse ways in which patients suffering from cancer make meaning in the face of grave illness."

In addition to articulating ideas about witchcraft and sorcery, patients in Rwanda often highlight infection as a possible cause of cancer and thus reject a sharp categorical distinction between the communicable and the non-communicable. This understanding reflects the local epidemiological reality of a double burden of disease that includes both communicable and non-communicable conditions (Livingston 2012). When symptoms appear, cancer patients are typically tested for infections initially. It is also in line with the contemporary biomedical project of preventing certain forms of cancer through vaccination. As Djordjevic puts it, Rwandan patients understand cancer "drawing on an infectious disease framework that has dominated their experience, in terms of treatment, public health discourses, and mass education campaigns."

While Djordjevic's piece contributes to anthropological approaches to medical pluralism, the essay by Dwaipayan Banerjee adds to our understanding of the plurality of biomedicine. Banerjee's essay, "Cancer and secrecy in contemporary India," approaches questions of elision, culture, and structural inequality from another perspective. He takes the secrecy and concealment of cancer diagnoses and prognoses in India as the object of inquiry. Most social science analyses take the issue of cancer non-disclosure to be a "cultural" phenomenon that is deemed to be either unethical and an obstacle to health or an ethical and compassionate way of caring for cancer patients. Banerjee, however, provides insights into the ways in which patients and their caretakers use disclosure and non-disclosure as a strategy for testing the strength or vulnerability of pre-existing relationships with relatives, neighbors, friends, and others within one's social network. He refuses to rely on a binary concept of knowledge (either you know, or you don't know) and foregrounds instead the idea of knowledge as a spectrum and a process. Disclosure, writes Banerjee, "is never a matter of all or nothing, but a dynamically shifting and negotiated site of social transaction." Taking his cue from Canguilhem who considered disease an experiment with life (Canguilhem 1989), Banerjee examines speaking about cancer as "experiments in social relations."

Although the practice of non-disclosure is usually considered to be a cultural peculiarity of the global South, when we consider the lives of Banerjee's interlocutors there is nothing "cultural" about this phenomenon. In this way, his piece demonstrates that we can truly appreciate the lived experience of cancer in India when we refuse to view it through stereotypical assumptions of stigma "born out of cultural beliefs about disease" and go beyond simplistic discourses of hope, willpower, and survivorship. At stake in disclosure are vulnerabilities in social relations.

The articles by Banerjee and Sivaramakrishnan demonstrate that global, national, and regional discourses of cancer in the global South past and present have not been solely pre-occupied with techno-scientific interventions (or the lack thereof); they have also foregrounded the need for compassion and the morality of cancer care. In Sivaramakrishnan's piece, we see how a rhetoric of outrage about the lack of compassionate cancer care, especially for marginalized women, 
helped fuel philanthropic campaigns for more public resources for cancer care. In Banerjee's essay, we can appreciate the varied experiences of living with cancer in the waxing and waning of compassionate care within families and public health institutions.

Marissa Mika's photo essay provides an inter-disciplinary approach to the study of cancer in the global South by combining history and ethnography. She adds a multi-media dimension to deepen our understanding of cancer care through deployment of a pastiche of photos, fieldnotes, and analysis. Mika's essay represents a historical ethnography of a forty-year-old pediatric and adult lymphoma oncology unit in Kampala, Uganda on the eve of its demolition. Established as a site for chemotherapy and clinical trials in Uganda's early postcolonial years, through a collaboration of American, British, and Ugandan institutions, this small-scale treatment center was the only place providing public oncology care in the country for four decades. Mika juxtaposes photographs of clinical objects and spaces with fieldnotes to evoke the everyday routines of nurses as they pragmatically make do with limited resources at hand while striving to not only treat their patients through mixing chemotherapy chemicals that arrive in incorrect doses, but also to mitigate the toxic hazards of their working conditions in the absence of protective gear. When donations-or seemingly "dumped" unwanted goods - of new protective gear arrive from the U.S., it helps to assuage nurses' fears of being poisoned through exposure, yet leads to other forms of discomfort and suffering in the absence of ventilation in this precarious clinical space. Mika documents the destruction of these oncology wards to make way for the construction of a larger and better-resourced oncology hospital and research center. Nevertheless, she concludes on a cautionary note that concerns for the safety of health workers as well as patients in public oncology wards, such as this one in Uganda, will remain a "defining feature of the growing cancer epidemic in the Global South in the years to come."

The four articles and the photo essay in this special issue all move away from the rhetoric of crisis and the simplistic analytics of abjection of cancer in the global South and underscore instead the political uses of such frameworks. Histories and ethnographies of cancer in the global South demand an accounting for the fragility of life in conditions that are shaped by complex social, political, technological, and economic forces. This fragility is not everywhere the same. A focus on the fragility of life-on failure and infelicity, on secrecy and avoidance, on the evanescent and the ephemeral, on the latent and the hesitant, on the obscure and the incoherent-will allow scholars of the global South to study precarity as experiment in meaning, morality and social relations, as openness to an obscure, indecipherable world, as uncertainty about the causes of an affliction, as skepticism about the outcome of a treatment, as exposure to toxic biomedical therapies, and as improvisation with scarce resources and incomplete solutions.

Acknowledgements We would like to thank the Editors of BioSocieties for the support throughout the publication process as well as the Wellcome Trust for the funding of the workshop in London. 


\section{References}

Adams, V., D. Behague, C. Caduff, I. Löwy, and F. Ortega. 2019. Re-imagining Global Health Through Social Medicine. Global Public Health 10: 1383-1400.

Armin, J., N. Burke, and L. Eichelberger (eds.). 2019. Negotiating Structural Vulnerability in Cancer Control. Albuquerque, NM: University of New Mexico Press.

Brandt, A. 2007. The Cigarette Century: The Rise, Fall, and Deadly Persistence of the Product That Defined America. New York: Basic Books.

Caduff, C., M. Skelton, D. Banerjee, D. Djordjevic, M. Mika, L. Mueller, K. Sivaramakrishnan, and C. Van Hollen. 2018. An Analysis of Social Science Research into Cancer Care in Low- and Middleincome Countries: Improving Global Cancer Control Through Greater Interdisciplinary Research. Journal of Global Oncology 4: 1-9.

Canguilhem, G. 1989. The Normal and the Pathological. Cambridge: MIT Press.

Comaroff, J., and J.L. Comaroff. 2012. Theory from the South: Or, How Euro-America Is Evolving Toward Africa. Boulder, CO: Paradigm Publishers.

Feachem, R., T. Kjellstrom, C. Murray, M. Over, and M. Phillips. 1992. The Health of Adults in the Developing World. Oxford: Oxford University Press.

Gregg, J.L. 2003. Virtually Virgins: Sexual Strategies and Cervical Cancer in Recife, Brazil. Palo Alto: Stanford University Press.

Livingston, J. 2012. Improvising Medicine. An African Oncology Ward in an Emerging Cancer Epidemic. Durham: Duke University Press.

Lora-Wainwright, A. 2013. Fighting for Breath: Living Morally and Dying of Cancer in a Chinese Village. Honolulu: University of Hawaii Press.

Martínez, R.G. 2018. Marked Women: The Cultural Politics of Cervical Cancer in Venezuela. Stanford: Stanford University Press.

Mukherjee, S. 2010. The Emperor of all Maladies: A Biography of Cancer. New York: Scribner.

Mathews, H., N. Burke, and E. Kampriani (eds.). 2017. Anthropologies of Cancer in Transnational Worlds. New York: Routledge.

Reubi, D., C. Herrick, and T. Brown. 2015. The Politics of Non-Communicable Diseases in the Global South. Health and Place 1-9.

WHO. 2005. Preventing Chronic Diseases-A Vital Investment. Geneva: WHO.

Publisher's Note Springer Nature remains neutral with regard to jurisdictional claims in published maps and institutional affiliations.

Carlo Caduff teaches in the Department of Global Health and Social Medicine at King's College London. His research explores global health at the intersection of science, medicine, media, and the state. He is the author of The Pandemic Perhaps: Dramatic Events in a Public Culture of Danger (University of California Press 2015). In 2019, he received an Investigator Award from the Welcome Trust to examine, over the next five years, the changing landscape of cancer care in India.

Cecilia C. Van Hollen is Professor and Head of Studies of Anthropology at Yale-NUS College. She is the author of Birth in the Age of AIDS: Women, Reproduction, and HIV/AIDS in India (Stanford University Press 2013) and Birth on the Threshold: Childbirth and Modernity in South India (University of California Press 2003). She is currently working on a third book project entitled, Cancer and the Kali Yuga: Responding to a Reproductive Cancer Crisis in India. 